\title{
Phenotypically divergent classification of preweaned heifer calves for feed efficiency indexes and their correlations with heat production and thermography
}

\author{
J. M. Leão, ${ }^{*}$ S. G. Coelho, ${ }^{*}$ F. S. Machado,† R. A. Azevedo, ${ }^{*}$ J. A. M. Lima, ${ }^{*}$ J. C. Carneiro, ${ }^{*}$ C. F. A. Lage, ${ }^{*}$ \\ A. L. Ferreira,† L. G. R. Pereira, † T. R. Tomich, $\dagger$ and M. M. Campos $\dagger^{1}$ \\ *Department of Animal Science, School of Veterinary, Federal University of Minas Gerais, Minas Gerais, 30161-970, Brazil \\ †Brazilian Agricultural Research Corporation (Empresa Brasileira de Pesquisa Agropecuária, EMBRAPA), \\ National Center for Research on Dairy Cattle, Minas Gerais, 36038-330, Brazil
}

\begin{abstract}
The aims of this study were (1) to assess if there is phenotypical divergence for feed efficiency (FE) during the preweaning phase; (2) if $\mathrm{FE}$ is correlated with heat production (HP) measured by the face mask method or (3) by surface skin temperature via thermography, and (4) whether these methods are applicable to preweaned calves. Holstein $\times$ Gyr heifer calves $(\mathrm{n}=36$, birth body weight $=32.4 \pm 6.6 \mathrm{~kg}$ ) were enrolled and on trial between 4 and 12 wk of age and were classified into 2 residual feed intake (RFI) and residual body weight gain (RG) groups: high efficiency (HE; RFI, $\mathrm{n}=10$; and $\mathrm{RG}, \mathrm{n}=9$ ) and low efficiency (LE; RFI, $\mathrm{n}=10$; and $\mathrm{RG}, \mathrm{n}=8)$. Calves were fed milk $(6 \mathrm{~L} / \mathrm{d})$ and solid feed (95\% starter and 5\% chopped Tifton 85 hay, as fed). Growth was monitored weekly and feed intake (milk and solid feed) daily, during the whole period. Gas exchanges $\left(\mathrm{O}_{2}\right.$ consumption and production of $\mathrm{CO}_{2}$ and $\mathrm{CH}_{4}$ ) were obtained using a face mask at $45 \pm 5 \mathrm{~d}$ of age and HP was estimated. Maximum temperatures were measured at 7 sites with an infrared camera at $62 \pm 7 \mathrm{~d}$ of age. There was divergence in RFI and RG. Respectively, HE and LE calves had RFI of -0.14 and $0.13 \mathrm{~kg} / \mathrm{d}$, and $R G$ of 0.05 and $-0.07 \mathrm{~kg} / \mathrm{d}$. Dry matter intake was $15 \%$ lower in HE-RFI compared with LE-RFI, but no differences were observed in average daily weight gain. Within the RG test, no differences were observed in dry matter intake or average daily gain. The HE-RFI calves consumed less $\mathrm{O}_{2}(\mathrm{~L} / \mathrm{d})$ and produced less $\mathrm{CO}_{2}(\mathrm{~L} / \mathrm{d})$. Heart rate and $\mathrm{HP}$ were lower for HE-RFI calves compared with LE-RFI. Residual feed intake was correlated with $\mathrm{HP}(\mathrm{r}=0.48), \mathrm{O}_{2}$ consumption $(\mathrm{r}=0.48), \mathrm{CO}_{2}$ production $(\mathrm{r}=0.48)$, and heart rate $(\mathrm{r}=0.40)$. No differences were observed in
\end{abstract}

Received November 7, 2017.

Accepted January 25, 2018.

${ }^{1}$ Corresponding author: mariana.campos@embrapa.br
HP and gas exchanges between RG groups. Methane production was null in both groups. Eye temperature measured by thermography was $0.5^{\circ} \mathrm{C}$ greater in $\mathrm{HE}$ RG than LE-RG calves. Differences in skin temperature between $\mathrm{HE}$ and LE calves were not observed at the other sites. These results support the hypothesis that calves are divergent for RFI, RG, and FE during preweaning and divergence tests are applicable during this phase. The face mask method described here is a useful tool for estimating differences in HP among phenotypically divergent RFI calves. Eye temperature measured by infrared thermography may have potential to screen phenotypically divergent RG calves.

Key words: calorimetry, residual feed intake, residual gain, thermography

\section{INTRODUCTION}

In dairy farming, approximately $60 \%$ of the production costs are related to feed (Ho et al., 2005). An alternative to reduce feeding costs and increase production efficiency would be to improve efficiency of feed usage (Berry et al., 2014). In addition to the economic aspect, greater efficiency results in reduced waste of natural resources and methane emissions (Waghorn and Hegarty, 2011), thus reducing environmental impacts.

Presently, residual feed intake (RFI) is the most used index of feed efficiency (Koch et al., 1963). Residual feed intake is independent of growth rate and BW. It is defined as the difference between realized intake and predicted intake, using a linear regression of individual intake as a function of mean metabolic body weight $\left(\mathbf{B W}^{0.75}\right)$ and ADG, where RFI is the residual term. Highly feed efficient animals present negative RFI (i.e., realized intake is smaller than predicted intake), whereas animals with low feed efficiency present positive RFI (i.e., realized intake is greater than predicted intake). In addition to RFI, other measurements of efficiency have been described. Residual body weight gain (RG) is similar to RFI, but instead of regressing feed intake 
on BW and ADG as for RFI, RG is obtained from the regression of ADG on feed intake and BW (Crowley et al., 2010). Hence, RG is positively associated with growth rate, but it is not associated with feed intake (Berry and Crowley, 2013).

Holstein heifer calves selected according to varying RFI during the growth phase presented divergences in RFI during the first lactation, even though the divergences were reduced at that time (Macdonald et al., 2014; Gilbert et al., 2017). It has been observed that this variation in RFI has moderate heritability $\left(\mathrm{h}^{2}=\right.$ 0.45, Crowley et al., 2010). Thus, the selection of lowRFI animals as replacements could be an interesting tool, given that the association between efficiency in early and adult life could reduce time and costs of feed efficiency research and increase the selection pressure for this trait. Few studies, however, have evaluated this trait during the preweaning phase.

Although the biological mechanisms controlling RFI have not been fully elucidated, differences in digestion, nutrient requirements, and biochemical efficiency of feed usage have been identified as important factors (Herd and Arthur, 2009). The greatest variation in feed efficiency is likely related to variation in energy expenditure (Paddock, 2010). Energy expenditure, also known as heat production, can be estimated using indirect calorimetry, which measures oxygen consumption and carbon dioxide and methane production by the animal (Paddock, 2010). Regulation of body temperature has also been identified as an important aspect of physiological variation that could contribute to feed conversion efficiency in dairy cows (Herd and Arthur, 2009). This is due to greater use of energy sources for production of metabolic heat in detriment of milk yield in animals with greater body temperature (Britt et al., 2003). The use of infrared thermography (IRT) is another method for measurement of surface (e.g., skin)

Table 1. Nutrient composition of hay, starter, and TMR (95\% starter and $5 \%$ hay) offered to preweaned heifer calves between 4 and 12 wk of age

\begin{tabular}{lrrr}
$\begin{array}{l}\text { Nutrient composition } \\
\text { (\%, unless otherwise } \\
\text { indicated; DM basis) }\end{array}$ & Hay & Starter & \multicolumn{1}{c}{ TMR } \\
\hline DM & 90.3 & 89.3 & 89.3 \\
CP & 13.6 & 22.2 & 21.8 \\
OM & 80.8 & 77.9 & 78.0 \\
Ether extract & 3.7 & 4.6 & 4.6 \\
NFC & 16.7 & 59.5 & 57.3 \\
NDF & 70.1 & 24.5 & 26.8 \\
ADF & 33.3 & 9.9 & 11.0 \\
Gross energy (kcal/kg) & $3,928.0$ & $3,728.0$ & $3,738.0$ \\
Ca & 0.8 & 2.0 & 1.9 \\
P & 0.3 & 0.5 & 0.5 \\
\hline
\end{tabular}

temperature, and allows obtainment of measurements in a noninvasive manner (Montanholi et al., 2008).

The objectives of this experiment were to evaluate if phenotypically divergent classification is observed in relation to RFI and RG of preweaned heifer calves, and to determine if measurements of heat production (estimated by indirect calorimetry with a face mask) and of surface body temperature (measured by IRT) could be applied to the selection of high-efficiency calves during the preweaning phase. Our hypothesis was that there is phenotypically divergent classification in preweaned calves and that high efficient animals produce less heat.

\section{MATERIALS AND METHODS}

This study was approved by the Ethics Committee of Embrapa Dairy Cattle, Brazil (protocol no. 02/2014). The experiment was conducted at the Embrapa Dairy Cattle Experimental Farm, located in Coronel Pacheco, Minas Gerais, Brazil.

\section{Calves, Housing, Management, and Treatments}

Holstein $\times$ Gyr $\mathrm{F}_{1}$ crossbred heifer calves $(\mathrm{n}=36$; $\mathrm{BW}$ at birth $=32.4 \pm 6.6 \mathrm{~kg}$, mean $\pm \mathrm{SD}$ ) born during the spring (October to December) were enrolled in the experiment. Immediately after birth, the calves were removed from their dams, weighed, and had their umbilical cords immersed in $10 \%$ iodine solution. Colostrum $(10 \%$ of birth BW; >50 g of IgG/L) was fed within $6 \mathrm{~h}$ after birth. Passive transfer of immunity was assessed using total serum protein. Blood samples were collected via jugular venipuncture within $48 \mathrm{~h}$ after birth, centrifuged at $1,800 \times g$ for $10 \mathrm{~min}$ at room temperature $\left(22-25^{\circ} \mathrm{C}\right)$, and total serum protein $(\mathrm{g} / \mathrm{dL})$ was measured using a refractometer (Serum protein REF-301, Biocotek, Beilun, Ningbo, China).

Calves were housed in sand-bedded individual pens $(1.25 \times 1.75 \mathrm{~m}$, tethered with 1.2 -m-long chains $)$, which were allocated in a barn with open sides and end-walls. Calves were fed $6 \mathrm{~L}$ of milk/d during the whole preweaning period, split into 2 equal meals offered at 0700 and $1400 \mathrm{~h}$. Calves were fed transition milk until $3 \mathrm{~d}$ of age and whole milk from $4 \mathrm{~d}$ of age until weaning. Water and solid feed were offered in buckets for ad libitum intake (10\% orts of solid feed) throughout the experimental period. Solid feed as-fed was composed of 95\% starter (Soylac Rumen 20\% Flocculated, Total Alimentos, Três Corações, Minas Gerais, Brazil) and $5 \%$ chopped Tifton 85 hay (Table 1). Growth was monitored weekly and feed intake (milk and solid feed) was monitored daily until d 82 of age, when all calves were abruptly weaned. 


\section{Handling and Health Measurements}

At d 8, preventive oral treatment against coccidiosis (Baycox Ruminants, Bayer, Leverkursen, Germany) was performed, at the dose of $3 \mathrm{~mL}$ per $10 \mathrm{~kg}$ of BW. Health and fecal scores were monitored daily by trained farm staff. Fecal score was graded according to Larson et al. (1977), as follows: 1, normal (firm, well formed); 2 , soft (tending to become slurred); 3 , loose (moderate diarrhea, slurred feces); and 4, watery (severe diarrhea, liquid feces). A heifer was considered to have diarrhea if fecal scores were 3 or 4 . All the episodes of diarrhea were in the first $2 \mathrm{wk}$ of life. All heifers were dehorned on the second week of life.

\section{Nutrient Composition Analyses}

Milk was sampled twice a day into plastic vials containing bronopol at each feeding for analysis of TS, $\mathrm{CP}$, lactose, and fat content. Milk component analysis was performed by spectrophotometry using Bentley 2000 (Bentley Instruments, Chaska, MN). Mean \pm SD values were $12.55 \% \pm 0.93 \mathrm{TS}, 3.93 \% \pm 1.06$ fat, $3.13 \%$ $\pm 0.16 \mathrm{CP}$, and $4.54 \% \pm 0.19$ lactose.

Samples of solid feed (hay and starter) and its orts were collected thrice per week, pooled into a weekly sample, and stored at $-20^{\circ} \mathrm{C}$ until analysis. Feed samples were dried in a forced-ventilation oven at $55^{\circ} \mathrm{C}$ for $72 \mathrm{~h}$, ground to $1 \mathrm{~mm}$ particle size in a Wiley Mill (model 3, Arthur H. Thomas Co., Philadelphia, PA), and analyzed for DM, CP, ether extract, ash, calcium, and phosphorus according to AOAC International (1995). Both NDF and ADF were determined according to the methods of Van Soest et al. (1991; Table 1). Gross energy was determined using an adiabatic bomb calorimeter (Parr Instrument Company, Moline, IL). Organic matter content was estimated as $\mathrm{OM}=100$ ash (AOAC, 1995). Nonfiber carbohydrates were calculated using the equation proposed by Hall et al. (1999): $\mathrm{NFC}_{a p}=100-\left(\mathrm{CP}+\mathrm{NDF}_{a p}+\right.$ ether extract + ash $)$, where subscript ap represents correction for ash and protein.

\section{Intake and Performance}

Daily solid feed was calculated by subtracting the orts from the offered quantities. Feed and water were weighed using a portable scale (WH-A04, WeiHeng, China). Daily milk intake was calculated as the sum of the differences between offered and refused amounts at morning and afternoon feedings. Solid and milk feed intake were measured between 4 and 12 wk of age. Calves were weighted at birth, at $3 \mathrm{~d}$ of age (i.e., when the experimental diet was first offered), and weekly thereafter. Calves were weighed before the morning milk feeding.

\section{Feed Efficiency Indexes}

Residual feed intake and RG were calculated over 56 observation days. Intake and performance were evaluated from 25 to $80 \mathrm{~d}$ of age. Total DMI was obtained from the sum of milk DMI and solid feed DMI (offered amount minus orts in a DM basis). Average daily weight gain was calculated as the linear regression coefficient of BW (PROC REG; ver. 9.0, SAS Institute Inc., Cary, $\mathrm{NC}$ ), composed of $9 \mathrm{BW}$ measurements per calf at 7-d intervals, and $\mathrm{BW}^{0.75}$ was calculated using the $\mathrm{BW}$ at $23 \mathrm{~d}$ of the test. Feed efficiency was measured using the relationship between mean daily DMI and ADG (Khan et al., 2007).

Dry matter intake, $\mathrm{BW}^{0.75}$, and $\mathrm{ADG}$ were used to estimate RFI and RG using linear regressions (Koch et al., 1963), where RFI and RG were calculated as the difference between realized and predicted DMI and ADG, respectively, as follows:

$$
\mathrm{Y}_{\mathrm{j}}=\beta_{0}+\beta_{1}\left(\mathrm{BW}_{\mathrm{j}}^{0.75}\right)+\beta_{2}\left(\mathrm{ADG}_{\mathrm{j}} \text { or } \mathrm{DMI}_{\mathrm{j}}\right)+\mathrm{e}_{\mathrm{j}},
$$

where $Y_{\mathrm{j}}$ is the standardized DMI (RFI) or ADG (RG) of calf $\mathrm{j}, \beta_{0}$ is the intercept, $\beta_{1}$ is the regression coefficient for $\mathrm{BW}^{0.75}, \beta_{2}$ is the regression coefficient for $\mathrm{ADG}$ (RFI) or DMI (RG), and $e_{j}$ is the error term for calf $j$.

Calves were classified into 2 RFI and RG groups: high efficiency [HE; RFI $<0.5$ SD below the mean ( $\mathrm{n}=$ 10) and $\mathrm{RG}>0.5 \mathrm{SD}$ above the mean $(\mathrm{n}=9)]$, and low efficiency $[\mathbf{L E}$; RFI $>0.5 \mathrm{SD}$ above the mean $(\mathrm{n}=10)$ and $\mathrm{RG}<0.5 \mathrm{SD}$ below the mean $(\mathrm{n}=8)]$.

\section{Heat Production}

Heat production was evaluated at $45 \pm 5 \mathrm{~d}$ of age. Three or 4 calves were evaluated each day. Calves were weighed before the morning milk feeding on the evaluation days, and the feed intake of the day before the first evaluation day was compared between groups. Calves were placed in a squeeze chute, the face mask was fitted, and the exchange of gases was evaluated for $30 \mathrm{~min}$ in 2 consecutive days, $3 \mathrm{~h}$ after the morning feeding, starting at $1000 \mathrm{~h}$. The delivery of diets on the evaluation days was planned to allow measurements approximately at $3 \mathrm{~h}$ postfeeding.

Respiratory gas exchanges were measured using a face mask adapted to calves according to the methodology described by Oss et al. (2016). The face mask was manufactured with a 5.2-L polyethylene bottle, containing a $16-\mathrm{cm}$ opening that covered the calf's muzzle up to the nasal bone, and was adapted to fit a halter. 
A flexible plastic membrane with a central hole with diameter of $6 \mathrm{~cm}$ was adapted to the superior external opening of the mask for pressure adjustment to the calf's snout and air sealing, thus blocking the movement of gases through this opening. Two flanges $(25$ $\mathrm{mm}$ length $\times 20 \mathrm{~mm}$ diameter) were adapted centrally to the external outer part of the mask for installation of 2 valves (non-rebreathing Era Mask Valves; Era Mask, Victoria, Australia) to guarantee entry of external air to the interior of the mask and to block the exit of exhaled air, to force all exhaled air to pass through the tubing that led to the flowmeter. A 50-mm flange and an adapter (40-mm screw flange) were plugged to the funnel-like extremity of the mask, where a flexible tubing with inner diameter of $20 \mathrm{~mm}$ (Kanaflex S/A Indústria de Plásticos, São Paulo, Brazil) was attached to connect the face mask to a $100-\mathrm{L}$ PVC container equipped with a plastic bag at its superior end, to guarantee sealing and adaptation to the calf's respiratory movements, thus avoiding respiratory effort and aiding to standardize the air flow to the analyzers. Another flexible tubing with inner diameter of $50.8 \mathrm{~mm}$ (Kanaflex S/A Indústria de Plásticos) connected the plastic container to a mass flowmeter (FK500, 75-500 L/min, Sable Systems, Las Vegas, NV). The PVC recipient's exit tubing was attached to a T-shaped rigid PVC joint (800 mm long $\times 50 \mathrm{~mm}$ across), placed longitudinally to contribute to the homogeneity of the internal air.

The rate of air flow through the mask (standard temperature and pressure corrected, $100 \mathrm{~L} / \mathrm{min}$ ) was controlled and measured by a mass flow controller (Flow Kit 500H, Sable Systems). The mass flow controller acquired sub-samples of air from the mask at $500 \mathrm{~mL} /$ min for analysis. Simultaneously, a positive pressure pump (B-pump, Sable Systems) acquired sub-samples of ambient air (baseline) at $500 \mathrm{~mL} / \mathrm{min}$. Face mask and the ambient air were continuously sampled through Bev-A-Line tubes to a gas switching system (RM- 8 Flow Multiplexer, Sable Systems) to deliver gas samples to the analyzer set via a diaphragm subsampling pump (SS-4 Sub-Sampler Pump) at $200 \mathrm{~mL} / \mathrm{min}$. Samples from the face mask and ambient air were collected at 1-min intervals over $20 \mathrm{~min}$; ambient air samples were also collected 5 min before and 5 min after the $20 \mathrm{~min}$ measurement to establish baseline gas levels. Humidity levels of the samples were monitored by a humidity meter (RH-300, Sable Systems), before flowing through $\mathrm{CO}_{2}$ (CA-10, Sable Systems), $\mathrm{CH}_{4}$ (MA-10, Sable Systems), and $\mathrm{O}_{2}$ (FC-10, Sable Systems) gas analyzers. All data were recorded by an automated data acquisition program (Expedata, Sable Systems). Considering the flow rate and the concentration of gases in the ambient air and in the air exiting the face mask, the software calculates the exhaustion rates $(\mathrm{L} / \mathrm{min})$ of $\mathrm{O}_{2}$
$\left(\mathbf{V O}_{2}\right)$ and $\mathrm{CO}_{2}\left(\mathbf{V C O}_{2}\right)$ and $\mathrm{CH}_{4}\left(\mathbf{V C H}_{4}\right)$ using the equations from Lighton (2008). Total daily consumption of gases $(\mathrm{L} / \mathrm{d})$ was calculated by extrapolation of per-minute data to daily data (multiplication by 1,440 ; $60 \min \times 24 \mathrm{~h})$.

The energy expenditure was calculated as the estimated heat production using the equation by Brouwer (1965); the production of urinary nitrogen was not considered in the calculations (Verstegen et al., 1987). The respiratory coefficient was calculated as the fractional $\mathrm{CO}_{2}$ production divided by $\mathrm{O}_{2}$ consumption.

The average heart rate measurements were recorded every $60 \mathrm{~s}$ and averaged over the $30 \mathrm{~min}$ of face mask evaluation. The heart rate was recorded using Polar equine transmitter and monitor (model RS800CX, Polar Electro Inc., Kempele, Finland). The transmitters were embedded in a 10-cm-wide strap with a Velcro latch placed around the calf's girth behind the shoulders. The negative electrode was positioned on the right side and the positive electrode on the opposite side of the calf's thorax, parallel to the left elbow. Conductivity gel was applied on the area around the electrodes for increased conductance. Oxygen pulse ( $\mathrm{mL} /$ heart beat) was determined as the average oxygen consumption per minute over the heart rate per minute during the face mask evaluation period.

\section{Infrared Thermography}

Thermal images of the calves were taken with an infrared camera (FLIR T420, FLIR Systems Inc., Wilsonville, OR) on d $62( \pm 7)$ at $0600 \mathrm{~h}$, before the morning feeding. The following standards were established for imaging: $0.5 \mathrm{~m}$ distance between the thermograph and the evaluated anatomical region, reflectance temperature of $20^{\circ} \mathrm{C}$, and emission value of 0.98 , according to the manufacturer's recommendations for biological tissues and to values used by Montanholi et al. (2008) and Montanholi et al. (2009). All thermal images were obtained in a roofed area. The evaluated anatomical regions were eye, cheek, snout, right-side ribs, left-side flank, right front limb, and hind area. Calves were manually restrained during the evaluations, with no manipulation of the evaluated areas. The average ambient temperatures recorded during imaging evaluations ranged between 18 and $25^{\circ} \mathrm{C}$ (relative humidity between 59 and 99\%). The generated images were processes and interpreted using the FLIR Tools 5.6 software (FLIR Systems Inc.).

To establish a constant area of evaluation, a figure was drawn on the image surface and it was then dragged to the region of the skin located in the chosen area (Gomes et al., 2016). Only the maximum temperature within each delimited area was considered, to 
reduce the interference of factors such as contamination by water, feces, urine, or contact with colder surfaces, which could influence the thermogram.

The rectal temperature of each animal was measured immediately after the IRT evaluations using a digital thermometer (TH198, GTech, Rio de Janeiro, Brazil).

\section{Statistical Analyses}

Data were analyzed using SAS version 9.0 (SAS Institute Inc., Cary, NC). Performance and DMI were evaluated as repeated measures using SAS PROC MIXED. The statistical model included fixed effects of treatment, time (week), treatment $\times$ time interaction, and the covariates described below. The experimental week was included as a REPEATED statement and calf was nested within treatment as random effect. Heat production variables were submitted to ANOVA. The comparison between means was done using the least squares means (LSMeans) test, where the significance level was set at $10 \%$ for all tests. Pearson correlation coefficients between the response variables and RFI and RG were obtained with PROC CORR. Birth BW and total serum protein were used as covariates in all analyses, and ambient temperature, humidity, and temperature-humidity index were used as covariates in the IRT analyses; covariates were kept in the models when their effect was significant.

\section{RESULTS AND DISCUSSION}

\section{Feed Efficiency Indexes}

High and low feed efficient calves were identified, where RFI was -0.14 and $0.13 \mathrm{~kg} / \mathrm{d}(P<0.01)$ for $\mathrm{HE}$ and LE, respectively. High-efficiency calves had lower DMI compared with low-efficiency calves $(P=0.06$; Table 2). Paddock (2010) affirmed that previous studies (Arthur et al., 2001a,b; Lancaster et al., 2005) have reported similar differences in DMI (15 to $22 \%$ lower for HE-RFI calves) and feed conversion rate (19 to $21 \%$ lower for HE-RFI calves) between RFI phenotypes. In our study, HE-RFI had feed efficiency $13 \%$ higher than LE-RFI $(P<0.01$; Table 2$)$. The correlation coefficient between DMI and RFI was $0.60(P<0.01)$, in agreement with Ceacero et al. (2016), who reported phenotypical correlation of 0.73 and genetic correlation of 0.68 between DMI and RFI.

Divergence was also observed for RG, which was $-0.07 \mathrm{~kg} / \mathrm{d}$ for the LE-RG group and $0.05 \mathrm{~kg} / \mathrm{d}$ for the HE-RG group $(P<0.01$; Table 2$)$. Negative values for RG are deemed to indicate more inefficient animals, whereas animals with positive RG values (i.e., animals growing faster than expected) are deemed to be more

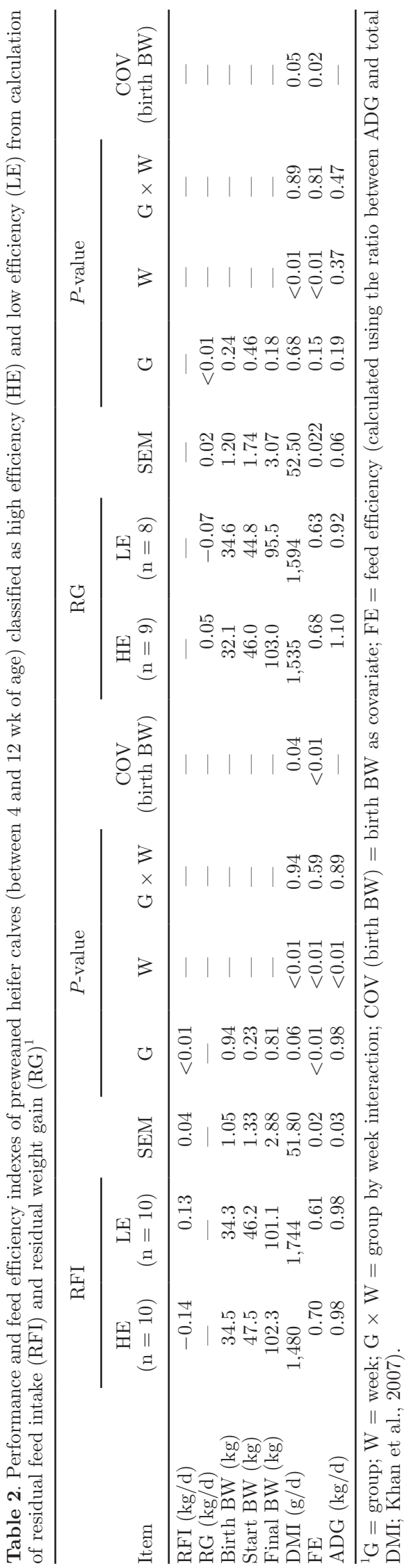


efficient (Berry and Crowley, 2013). No difference was observed in DMI between groups of HE-RG and LE-RG. Crowley et al. (2010) and Berry and Crowley (2012) reported null genetic correlations between RG and DMI in cattle of European breeds. Crowley et al. (2010) reported a genetic correlation between RG and increased growth rate of 0.70 , but no differences were observed in DMI between high and low phenotypic RG. Santana et al. (2014) estimated negative genetic correlations of -0.12 between RG and DMI in Nellore cattle, in agreement with the results presented here.

To our knowledge, this is the first study evaluating feed efficiency divergence in preweaned dairy calves, which is complicated due to the large difference between milk and starter nutritional value and digestion. To produce results useful for dairy industry, the experiment followed the feeding management practices adopted in commercial farms, which consisted of supplying a set amount of milk and then allowing the calves to have ad libitum starter. Although this practice represents commercial rearing conditions, it limits the understanding of the separate effects of milk and starter feed. Therefore, it is not possible to determine whether variations occurring in certain variables result from milk or from starter feed or to understand possible interactions among them.

Because the supply of milk was restricted $(6 \mathrm{~L} / \mathrm{d})$ for all animals over the trial, the variation in intake among calves would be related to the difference in solid feed intake. Individual daily intakes of milk and starter were accurately measured. The animals evaluated for HE-RFI and LE-RFI had the same intake of milk 838 $\mathrm{g}$ of DM/d on trial between 4 and 12 wk of age. Highefficiency RFI had lower intake of solid feed, $543 \mathrm{~g}$ of $\mathrm{DM} / \mathrm{d}$ compared with LE-RFI, $798 \mathrm{~g}$ of $\mathrm{DM} / \mathrm{d}(P=$
$0.03)$. For the $2 \mathrm{RG}$ groups, no difference was present in milk intake, $835 \mathrm{~g}$ of $\mathrm{DM} / \mathrm{d}$, and for solid feed intake, $628 \mathrm{~g}$ of $\mathrm{DM} / \mathrm{d}$.

Average daily gain was similar between $\mathrm{HE}$ and LE calves during the RFI and RG test-period $(0.97 \pm 0.1$ $\mathrm{kg} / \mathrm{d}$ ). A meta-analysis by Berry and Crowley (2013) reported an estimate of 0.02 for the genetic correlation between RFI and ADG. Santana et al. (2014) observed genetic and phenotypic correlations of 0.11 and 0.05 , respectively, between RFI and ADG for Nellore cattle, as well as genetic and phenotypic correlations of 0.12 and 0.20 , respectively, between RG and ADG, in agreement with Berry and Crowley (2013). Herd and Arthur (2009) demonstrated similar BW and ADG that supports the independence of RFI from production. Average daily gain was correlated with $\mathrm{RG}(\mathrm{r}=0.15 ; P=$ $0.03)$.

Birth BW and BW at the start of the test (wk 4) were similar between groups within RFI and RG tests (Table 2). Due to similar ADG at the end of the test period, BW was similar between HE and LE groups for RFI and RG evaluations $(P>0.05)$.

\section{Heat Production and Gas Exchanges}

Heat production $\left(\mathrm{kcal} / \mathrm{d}\right.$ per $\mathrm{BW}^{0.75}$ ) was lower for HE-RFI animals compared with LE-RFI animals $(P$ $=0.03$, Table 3 ). Calves with LE-RFI lost $15.3 \%$ more energy in the form of heat production $(\mathrm{kcal} / \mathrm{d})$ than HE-RFI calves. Nkrumah et al. (2006) reported heat production 21 and $10 \%$ lower for high and medium efficiency RFI steers than for steers with low-efficiency RFI, respectively.

Heart rates were greater $(P=0.03$, Table 3$)$ for LE-RFI group compared with HE-RFI group, which

Table 3. Dry matter intake on evaluation day, heat production, and gas exchange in preweaned dairy heifer calves (45 $\pm 5 \mathrm{~d}$ of age) classified as high efficiency (HE) and low efficiency (LE) by residual feed intake (RFI) and residual gain (RG) ${ }^{1}$

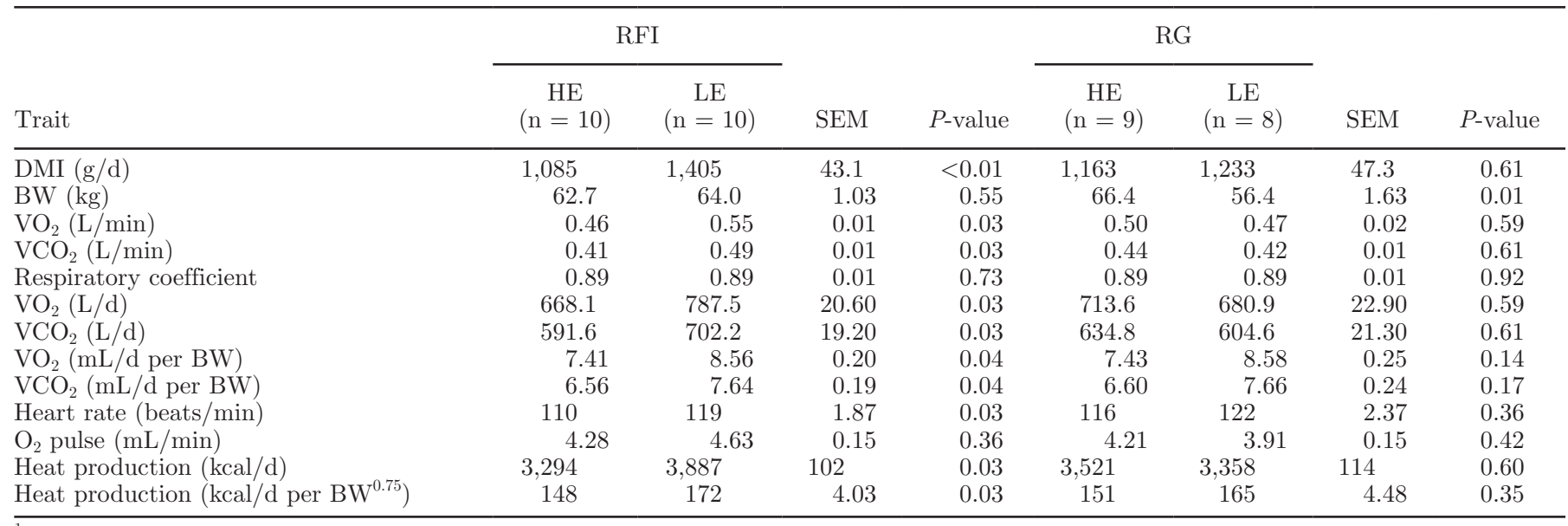

${ }^{1} \mathrm{VO}_{2}=$ volume of $\mathrm{O}_{2} ; \mathrm{VCO}_{2}=$ volume of $\mathrm{CO}_{2}$. 
is similar to observations by Paddock (2010), who reported greater heart rates and oxygen pulse rates $(P$ $<0.05$ ) in heifers with low-efficiency RFI compared with those high-efficiency RFI. Paddock (2010) also estimated that energy expenditure ( $\mathrm{kcal} / \mathrm{BW}^{0.75}$ ) to be $17.4 \%$ greater $(P<0.05)$ in low-efficiency RFI heifers than in high-efficiency RFI heifers. Lancaster et al. (2005) reported that growing heifers and bulls with low-efficiency RFI had faster heart rates than those with high-efficiency RFI. There was no difference in $\mathrm{O}_{2}$ pulse rate for RFI and RG groups $(P>0.05$, Table 3$)$ in our study, differing from results reported by Paddock (2010).

Animals of HE-RFI had lower $\mathrm{O}_{2}$ consumption $(\mathrm{L} / \mathrm{d})$ and lower $\mathrm{CO}_{2}$ production expressed in $\mathrm{L} / \mathrm{d}(P=0.03)$ in comparison with the LE-RFI group. No differences were present in heat production and gas exchanges between RG groups $(P>0.05$; Table 3$)$. Correlations were observed between RFI and heat production $(\mathrm{r}=$ $0.48, P<0.01)$, RFI and $\mathrm{O}_{2}$ consumption $(0.48, P<$ $0.01), \mathrm{RFI}$ and $\mathrm{CO}_{2}$ production $(0.48, P<0.01)$, and RFI and heart rate $(0.40, P=0.01$; Table 4$)$. Methane production was null in all groups.

Cows that convert feed gross energy to net energy more efficiently or that have lower than expected maintenance requirements based on BW use less feed than expected and are classified as negative RFI; thus, such cows are considered high-efficiency animals. Cows classified as HE-RFI likely digest and metabolize nutrients more efficiently and should have an overall greater efficiency and profitability if they are also healthy, fertile, and produce at a high multiple of maintenance (VandeHaar et al., 2016). In the present experiment, we have observed similar characteristics for heifer calves, where HE-RFI calves converted smaller quantities of feed more efficiently, consequently producing a smaller amount of heat. A lower caloric increment of feeding is expected in animals that have reduced intake and similar performance (Herd and Arthur, 2009).
According to Nkrumah et al. (2006), the identification of metabolic and physiological reasons underlying the variation in feed efficiency in cattle that have similar BW and growth rate is a well-recognized prerequisite for the effective planning of breeding strategies to select more efficient animals. In their study, several potential metabolic and physiological pathways that could influence feed efficiency were considered. These included pathways that were generally related to variations in the efficiency of conversion of gross energy into ME (because of differences in digestibility, generation of gases during ruminal fermentation, absorption of nutrients, waste excretion, and heat production) and the subsequent efficiency of ME use for maintenance and growth. We suggest that more research on feed efficiency of calves is needed to improve the understanding of its variation in this category of cattle.

Nkrumah et al. (2006) also reported greater heat production in low versus HE-RFI steers, despite the lack of differences in gross energy intake, which might be attributable to variation in metabolic efficiency. Variation in energy expenditure associated with differences in size of visceral organs has been proposed by Basarab et al. (2003) as a significant contribution to differences in HP between animals that have different RFI. Residual feed intake is positively correlated with DMI (0.71; Paddock, 2010), and it has been demonstrated that an increased DMI in cattle is generally accompanied by significant increases in the size of visceral organs (Ferrell and Jenkins, 1998).

There were no differences in BW at birth, at $1 \mathrm{wk}$ of age, at the start of RFI evaluation (4th wk), or at the end of the experimental period (12th wk). In addition, ADG was not different between groups during the entire period (Table 2). It has been reported that RFI is repeatable within animal at different rearing phases, as the selection of animals based on RFI during the growth phase was predictive of the RFI rank of lactating cows (Macdonald et al., 2014) and of veal

Table 4. Correlations between feed efficiency indexes (RFI and RG) and gas exchanges, heat production, and heart rate of preweaned dairy heifer calves (between 4 and 12 wk of age $)^{1}$

\begin{tabular}{|c|c|c|c|c|}
\hline \multirow[b]{2}{*}{ Trait } & \multicolumn{2}{|c|}{ RFI } & \multicolumn{2}{|c|}{ RG } \\
\hline & $\mathrm{r}$ & $P$-value & $\mathrm{r}$ & $P$-value \\
\hline $\mathrm{VO}_{2}(\mathrm{~L} / \mathrm{min})$ & 0.48 & $<0.01$ & -0.01 & 0.93 \\
\hline $\mathrm{VCO}_{2}(\mathrm{~L} / \mathrm{min})$ & 0.48 & $<0.01$ & -0.01 & 0.95 \\
\hline $\mathrm{VO}_{2}(\mathrm{~L} / \mathrm{d})$ & 0.48 & $<0.01$ & -0.01 & 0.93 \\
\hline $\mathrm{VCO}_{2}(\mathrm{~L} / \mathrm{d})$ & 0.48 & $<0.01$ & -0.01 & 0.95 \\
\hline $\mathrm{VO}_{2}\left(\mathrm{~L} / \mathrm{d}\right.$ per $\left.\mathrm{BW}^{0.75}\right)$ & 0.46 & $<0.01$ & -0.29 & 0.10 \\
\hline $\mathrm{VCO}_{2}\left(\mathrm{~L} / \mathrm{d}\right.$ per $\left.\mathrm{BW}^{0.75}\right)$ & 0.46 & $<0.01$ & -0.27 & 0.13 \\
\hline Heart rate (beat/min) & 0.40 & 0.01 & -0.15 & 0.40 \\
\hline Heat production $(\mathrm{kcal} / \mathrm{d})$ & 0.48 & $<0.01$ & -0.01 & 0.93 \\
\hline Heat production $\left(\mathrm{kcal} / \mathrm{d}\right.$ per $\mathrm{BW}^{0.75}$ ) & 0.48 & $<0.01$ & -0.23 & 0.20 \\
\hline
\end{tabular}


calves (Gilbert at al., 2017). Furthermore, differences in gene expression associated with protein turnover and associated heat production in metabolically active tissues such as the liver and the gastrointestinal tract have been hypothesized as an alternative for increased understanding of the molecular mechanisms leading to variations in energy expenditure in cattle of similar BW and ADG (Nkrumah et al., 2006).

\section{Infrared Thermography}

Montanholi et al. (2009) reported that less efficient animals have greater heat production and present greater body surface temperature than more efficient animals, which is not in agreement with our observations for LE-RG and HE-RG calves. Eye temperatures were significantly greater $\left(0.5^{\circ} \mathrm{C}\right)$ in HE-RG calves compared with LE-RG calves $(P=0.08$; Table 5$)$. No other significant differences in skin temperature at any of the measured sites were noted between $\mathrm{HE}$ and LE groups. However, Martello et al. (2016) also observed that temperatures of the front measured by IRT were lower $(P<0.01)$ for low-efficiency RFI cattle than for high-efficiency RFI cattle, and that the greater skin temperature measured by IRT for animals in the highefficiency RFI group may be related to an improved efficiency of thermoregulatory mechanisms, as the rectal temperature remained lower in the high-efficiency RFI group. Those authors suggested that the greater skin temperature in the high-efficiency group probably occurred due to an effect of heat dissipation on maintenance of lower body core temperature in high-efficiency animals compared with the low-efficiency RFI group.

Although the mean rectal temperature value was not indicative of caloric stress, the maximum rectal temperature of $39.8^{\circ} \mathrm{C}$ observed by Martello et al. (2016) is above the normal physiological condition for ruminants. In our study, the maximum rectal temperature was $39.1^{\circ} \mathrm{C}$. Skin temperature reflects heat dissipation (Scharf et al., 2010), whereas the ocular surface is representative of the core body temperature (Dunbar et al., 2009). Correlations were observed between eye temperature measured by IRT and RG $(0.40 ; P=0.02)$, demonstrating that the same could be occurring with the calves in the present study.

Scientific understanding of the physiological phenotype of low- and high-efficiency calves is poor and further knowledge of the physiological differences between animals of different efficiencies is required to develop a suite of potential indices for improved selection of more efficient animals. The IRT technique was not suitable for the investigation of our hypothesis, and more studies with calves are needed to evaluate these results.

\section{CONCLUSIONS}

The feed efficiency divergence tests are applicable to preweaned calves, as divergence in RFI and RG were observed during this rearing phase. The face mask method described here is a useful tool for estimating heat production differences in calves that present divergence in phenotypic RFI. Eye temperatures measured by IRT may have potential for screening phenotypically divergent RG calves.

\section{ACKNOWLEDGMENTS}

The authors thank Coordenação de Aperfeiçoamento de Pessoal de Nível Superior (CAPES, Brasília, Brazil), Fundação de Amparo à Pesquisa do Estado de Minas Gerais (FAPEMIG, Minas Gerais, Brazil), Conselho Nacional de Desenvolvimento Científico e Tecnológico (CNPq, Minas Gerais, Brazil), and Embrapa Dairy Cattle (Minas Gerais, Brazil) for financially supporting this research.

Table 5. Ambient temperature and temperature of different body sites $\left({ }^{\circ} \mathrm{C}\right)$ of preweaned dairy heifer calves $(62 \pm 7 \mathrm{~d}$ of age $)$ classified as high efficiency (HE) and low efficiency (LE) from calculation of residual feed intake (RFI) and residual gain (RG) measured by infrared thermography ${ }^{1}$

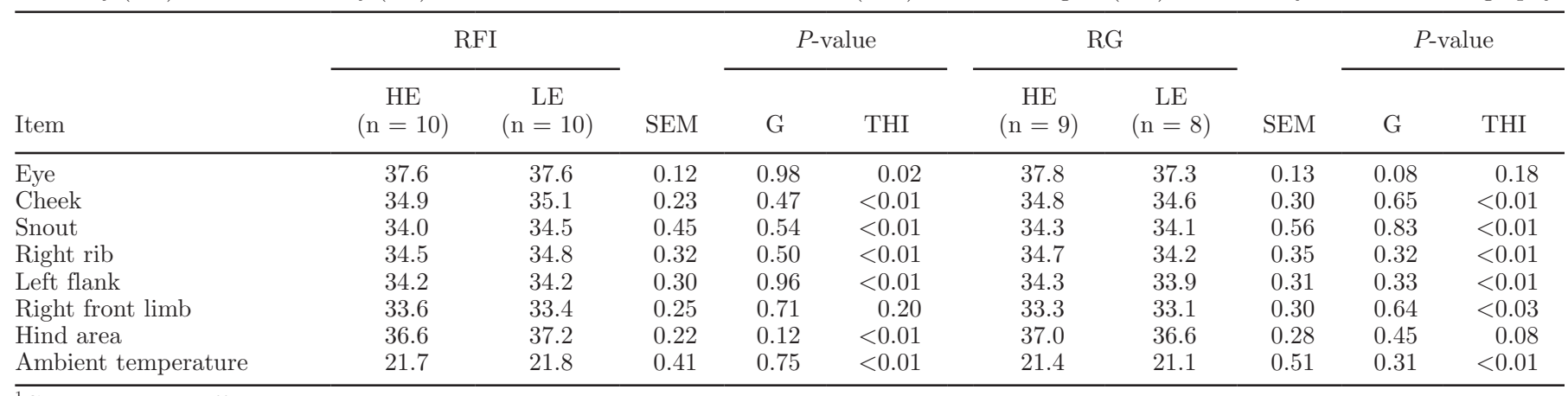

${ }^{1} \mathrm{G}=$ statistical difference between $\mathrm{HE}$ and LE; THI = temperature-humidity index. 


\section{REFERENCES}

AOAC International. 1995. Official Methods of Analysis of AOAC International. 16th ed. Chapter 4: Animal Feed. Windham, W. R. AOAC International, Arlington, VA.

Arthur, P. F., J. A. Archer, D. J. Johnston, R. M. Herd, E. C. Richardson, and P. F. Parnell. 2001a. Genetic and phenotypic variance and covariance components for feed intake, feed efficiency, and other postweaning traits in Angus cattle. J. Anim. Sci. 79:28052811.

Arthur, P. F., G. Renand, and D. Krauss. 2001b. Genetic and phenotypic relationships among different measures of growth and feed efficiency in young Charolais bulls. Livest. Prod. Sci. 68:131-139.

Basarab, J. A., M. A. Price, J. L. Aalhus, E. K. Okine, W. M. Snelling, and K. L. Lyle. 2003. Residual feed intake and body composition in young growing cattle. Can. J. Anim. Sci. 83:189-204.

Berry, D. P., M. P. Coffey, J. E. Pryce, Y. De Haas, P. Løvendahl, N. Krattenmacher, and K. Macdonald. 2014. International genetic evaluations for feed intake in dairy cattle through the collation of data from multiple sources. J. Dairy Sci. 97:3894-3905.

Berry, D. P., and J. J. Crowley. 2012. Residual intake and body weight gain: A new measure of efficiency in growing cattle. J. Anim. Sci. 90:109-115.

Berry, D. P., and J. J. Crowley. 2013. Cell biology symposium: Genetics of feed efficiency in dairy and beef cattle. J. Anim. Sci. 91:1594-1613

Britt, J. S., R. C. Thomas, N. C. Speer, and M. B. Hall. 2003. Efficiency of converting nutrient dry matter to milk in Holstein herds. J. Dairy Sci. 86:3796-3801.

Brouwer, E. 1965. Report of sub-committee on constants and factors. Pages 441-443 in Energy Metabolism. EAAP Publ. No. 11. Academic Press, New York, NY.

Ceacero, T. M., M. E. Z. Mercadante, J. N. D. S. G. Cyrillo, R C. Canesin, S. F. M. Bonilha, and L. G. de Albuquerque. 2016 Phenotypic and genetic correlations of feed efficiency traits with growth and carcass traits in Nellore cattle selected for postweaning weight. PLoS One 11:e0161366.

Crowley, J. J., M. McGee, D. A. Kenny, D. H. Crews, R. D. Evans, and D. P. Berry. 2010. Phenotypic and genetic parameters for different measures of feed efficiency in different breeds of Irish performancetested beef bulls. J. Anim. Sci. 88:885-894.

Dunbar, M. R., S. R. Johnson, J. C. Rhyan, and M. McCollum. 2009. Use of infrared thermography to detect thermographic changes in mule deer (Odocoileus hemionus) experimentally infected with foot-and-mouth disease. J. Zoo Wildl. Med. 40:296-301.

Ferrell, C. L., and T. G. Jenkins. 1998. Body composition and energy utilization by steers of diverse genotypes fed a high-concentrate diet during the finishing period: I. Angus, Belgian Blue, Hereford, and Piedmontese sires. J. Anim. Sci. 76:637-646.

Gilbert, M. S., J. J. G. C. Van den Borne, C. G. Van Reenen, and W. J. J. Gerrits. 2017. Only 7\% of the variation in feed efficiency in veal calves can be predicted from variation in feeding motivation, digestion, metabolism, immunology, and behavioral traits in early life. J. Dairy Sci. 100:8087-8101.

Gomes, R. A., K. C. Busato, M. M. Ladeira, K. A. Johnson, M. C. Galvão, A. C. Rodrigues, D. Lourençoni, and M. L. Chizzotti. 2016. Technical note: Relationship between infrared thermography and heat production in young bulls. J. Anim. Sci. 94:1105-1109.

Hall, M. B., W. H. Hoover, J. P. Jennings, and T. K. M. Webster. 1999. A method for partitioning neutral detergent-soluble carbohydrates. J. Sci. Food Agric. 79:2079-2086.

Herd, R. M., and P. F. Arthur. 2009. Physiological basis for residual feed intake. J. Anim. Sci. 87:E64-E71.

Ho, C., R. Nesseler, P. Doyle, and B. Malcolm. 2005. Future dairy farming systems in irrigation regions. AFBM J. 2:59-68.

Khan, M. A., H. J. Lee, W. S. Lee, H. S. Kim, K. S. Ki, T. Y. Hur, G. H. Suh, S. J. Kang, and Y. J. Choi. 2007. Structural growth, rumen development, and metabolic and immune responses of Holstein male calves fed milk through step-down and conventional methods. J. Dairy Sci. 90:3376-3387.
Koch, R. M., L. A. Swiger, D. Chambers, and K. E. Gregory. 1963. Efficiency of feed use in beef cattle. J. Anim. Sci. 22:486-494.

Lancaster, P. A., B. R. Schilling, G. E. Carstens, E. G. Brown, T. M. Craig, and D. K. Lunt. 2005. Correlations between residual feed intake and carcass traits in finishing steers administered anthelmintic treatments. J. Anim. Sci. 83(Suppl. 1):263. (Abstr.)

Larson, L. L., F. G. Owen, J. L. Albright, R. D. Appleman, R. C. Lamb, and L. D. Muller. 1977. Guidelines toward more uniformity in measuring and reporting calf experimental data. J. Dairy Sci. 60:989-991.

Lighton, J. R. B. 2008. Measuring Metabolic Rates: A Manual for Scientists. Oxford University Press, Oxford, UK.

Macdonald, K. A., J. E. Pryce, R. J. Spelman, S. R. Davis, W. J. Wales, G. C. Waghorn, and B. J. Hayes. 2014. Holstein-Friesian calves selected for divergence in residual feed intake during growth exhibited significant but reduced residual feed intake divergence in their first lactation. J. Dairy Sci. 97:1427-1435.

Martello, L. S., S. L. Silva, R. C. Gomes, R. R. P. S. Corte, and P. R. Leme. 2016. Infrared thermography as a tool to evaluate body surface temperature and its relationship with feed efficiency in Bos indicus cattle in tropical conditions. Int. J. Biometeorol. 60:173-181.

Montanholi, Y. R., N. E. Odongo, K. C. Swanson, F. S. Schenkel, B. W. Mcbride, and S. P. Miller. 2008. Application of infrared thermography as an indicator of heat and methane production and its use in the study of skin temperature in response to physiological events in dairy cattle (Bos taurus). J. Therm. Biol. 33:469-475.

Montanholi, Y. R., K. C. Swanson, F. S. Schenkel, B. W. McBride, T. R. Caldwell, and S. P. Miller. 2009. On the determination of residual feed intake and associations of infrared thermography with efficiency and ultrasound traits in beef bulls. Livest. Sci. 125:22-30.

Nkrumah, J. D., E. K. Okine, G. W. Mathison, K. Schmid, C. Li, J. A Basarab, M. A. Price, Z. Wang, and S. S. Moore. 2006. Relationships of feedlot feed efficiency, performance, and feeding behavior with metabolic rate, methane production, and energy partitioning in beef cattle. J. Anim. Sci. 84:145-153.

Oss, D. B., M. I. Marcondes, F. S. Machado, L. G. R. Pereira, T. R Tomich, G. O. Ribeiro, and A. V. Chaves. 2016. An evaluation of the face mask system based on short-term measurements compared with the sulfur hexafluoride (SF 6) tracer, and respiration chamber techniques for measuring $\mathrm{CH} 4$ emissions. Anim. Feed Sci. Technol. 216:49-57.

Paddock, Z. D. 2010. Energy expenditure in growing heifers with divergent residual feed intake phenotypes, effects and interactions of metaphylactic treatment and temperament on receiving steers. MS thesis. Texas A\&M University, College Station.

Santana, M. H., Y. T. Utsunomiya, H. H. Neves, R. C. Gomes, J. F. Garcia, H. Kumasu, and R. A. Brassaloti. 2014. Genome-wide association analysis of feed intake and residual feed intake in Nellore cattle. BMC Genet. 15:21.

Scharf, B., J. A. Carroll, D. G. Riley, C. C. Chase, S. W. Coleman, D. H. Keisler, R. L. Weaber, and D. E. Spiers. 2010. Evaluation of physiological and blood serum differences in heat-tolerant (Romosinuano) and heat-susceptible (Angus) Bos taurus cattle during controlled heat challenge. J. Anim. Sci. 88:2321-2336.

Van Soest, P. J., J. B. Robertson, and B. A. Lewis. 1991. Methods for dietary fiber, neutral detergent fiber, and nonstarch polysaccharides in relation to animal nutrition. J. Dairy Sci. 74:3583-3597.

VandeHaar, M. J., L. E. Armentano, K. Weigel, D. M. Spurlock, R. J. Tempelman, and R. Veerkamp. 2016. Harnessing the physiology of the modern dairy cow to continue improvements in feed efficiency. J. Dairy Sci. 99:4941-4954.

Verstegen, M. W. A., W. Van der Hel, H. A. Brandsma, A. M. Henken, and A. M. Bransen. 1987. The Wageningen respiration unit for animal production research: A description of the equipment and its possibilities. Pages 21-48 in Energy Metabolism in Farm Animals. Springer Netherlands.

Waghorn, G. C., and R. S. Hegarty. 2011. Lowering ruminant methane emissions through improved feed conversion efficiency. Anim. Feed Sci. Technol. 166:291-301. 